\title{
HER-2 positivity is a high risk of recurrence of stage I gastric cancer
}

\author{
Seonhoo Kim, Yeon-Ji Kim, and Woo Chul Chung
}

Department of Internal Medicine, St. Vincent's Hospital, College of Medicine, The Catholic University of Korea, Suwon, Korea

\author{
Received: May 21, 2020 \\ Revised : July 22, 2020 \\ Accepted: October 17, 2020 \\ Correspondence to \\ Woo Chul Chung, M.D. \\ Division of Gastroenterology, \\ Department of Internal \\ Medicine, St. Vincent's Hospital, \\ College of Medicine, The Catholic \\ University of Korea, 93 Jungbu- \\ daero, Paldal-gu, Suwon 16247, \\ Korea \\ Tel: $+82-31-881-8582$ \\ Fax: $+82-31-253-8898$ \\ E-mail:jwchulkr@catholic.ac.kr \\ https://orcid.org/0000-0003- \\ 1044-0440
}

Background/Aims: The treatment of gastric cancer remains unsatisfactory. We aimed to investigate the prognostic value of immunohistochemical staining in gastric cancer.

Methods: We analyzed 505 (279 early staged, 226 advanced-staged) gastric cancer tissues from patients who underwent radical gastric resection between January 2014 and December 2016. Available surgical specimens immunohistochemically stained for p53, epidermal growth factor receptor (EGFR), human EGFR 2 (HER-2), E-cadherin, and Ki-67 were reviewed. We evaluated the association between positivity to various biomarkers and disease recurrence, disease-free survival, lymph node metastasis, and microscopic lymphovascular invasion.

Results: The median follow-up duration was 32.5 months (range, 7 to 70 ). Advanced gastric cancer cases showed high Ki-67 expression; other cases showed unremarkable expression. Concerning disease recurrence, lymphatic invasion, and disease-free interval, all biomarkers had no prognostic effects. HER-2-positive stage I gastric cancer tended to occur in old patients and in the upper one-third of the stomach $(p=0.01)$. HER-2 positivity was significantly correlated with disease recurrence $(p=0.01)$, lymphatic invasion $(p=0.03)$, and vascular invasion $(p=0.03)$ in stage I cases.

Conclusions: Only HER-2 was associated with the recurrence of stage I gastric cancer. HER-2-positive stage I gastric cancer requires additional therapy despite curative resection.

Keywords: Stomach neoplasms; Recurrence; Genes erbB-2

\section{INTRODUCTION}

Gastric cancer is a highly lethal malignancy and a serious public health concern, despite the worldwide decline in the incidence of this disease in the past century. It is still the fourth most common malignancy and the second most common cause of cancer-related deaths $[1,2]$. As a result of advances in surgical techniques and the development of anticancer agents, the survival of patients with gastric cancer has improved. Nevertheless, the best way to improve patient survival in gastric cancer is early detection through a regular screening protocol. In countries with a high prevalence of gastric cancer, such as Korea and Japan, gastric cancer screening is common at present. Recently, it has been proven that the gastric cancer-specific mortality has decreased and the survival rate of patients has improved owing to nationwide endoscopic gastric cancer screening. On the other hand, after it became clear that Helicobacter pylori infection is an important risk factor for gastric cancer, eradication therapy for $H$. pylori was applied and has reduced the incidence of gastric cancer worldwide [3]. 
Furthermore, since the late 2000s, the administration of adjuvant chemotherapy after curative surgery has been accepted as a standard treatment after the publication of large-scale phase III studies including the Adjuvant Chemotherapy Trial of TS-1 for Gastric Cancer (ACTSGC) and Adjuvant Capecitabine and Oxaliplatin for Gastric Cancer after D2 Gastrectomy (CLASSIC) trials $[4,5]$.

Nonetheless, when gastric cancer is detected at an advanced stage, the 5 -year survival rate is $<30 \%$ and the incidence of tumor recurrence or metastasis after curative resection is $>50 \%[6,7]$. These results are surprising and disappointing. Therefore, there is an urgent need for better prognostic biomarkers that could help improve the prediction of recurrence and metastasis. Early detection of gastric cancer recurrence has contributed to prompt management and is directly linked to prolonged survival. Moreover, a biomarker of therapeutic responsiveness could aid in the prediction of disease recurrence in patients with gastric cancer.

Several methods including immunohistochemical (IHC) staining for the detection of genetic mutations have been applied to identify the prognosis of diseases. However, it remains unclear whether specific biomarkers have prognostic value in gastric cancer treatment. The aim of this study was to evaluate the possible associations between genetic mutations detected using IHC staining and the prognostic factors of gastric cancer, including early disease stage, disease recurrence, disease-free survival (DFS), lymph node metastasis, and lymphovascular invasion.

\section{METHODS}

\section{Patients}

This was a retrospective cohort study of all cases of surgically resected gastric cancer at St. Vincent's Hospital, The Catholic University of Korea, from January 2014 to December 2016. This study was approved by the Institutional Review Board of St. Vincent's Hospital, The Catholic University of Korea (approval no. VC19RESIoo70). Informed consent was waived by the board.

We evaluated a total of 505 patients. Patients who underwent curative gastric resection or palliative operation and who were identified as having histologic gastric adenocarcinoma were eligible for inclusion. Patients were excluded if they had a history of other cancers. All included patients were followed up for $>3$ months after surgery.

Clinical data such as age, sex, weight, and height at the time of surgery were collected, and histopathologic features including depth of invasion, histologic type, microscopic lymphovascular invasion, and lymph node metastasis were analyzed. The pathologic cancer stage was interpreted according to the evaluation protocol recommended by the 7 th edition of the American Joint Committee on Cancer tumor, node, metastasis (TNM) classification [8]. Early gastric cancer (EGC) was defined as cancer in which the tumor cells were confined to the mucosa and submucosa regardless of lymph node metastasis. Recurrence was confirmed radiographically and/or pathologically and described as loco-regional or distant.

\section{Immunohistochemistry}

IHC analysis for p53, epidermal growth factor receptor (EGFR), human EGFR 2 (HER-2), E-cadherin, and Ki-67 was performed on tumor sections. We performed IHC staining using tissue microarray sections and a BenchMark XT autostainer (Ventana Medical Systems, Tucson, AZ, USA), according to the manufacturer's protocol. The commercially available antibody used for the IHC analysis of E-cadherin, EGFR, and p53 was clone 36/E-cadherin (1:50; BD Biosciences, Rockville, MD, USA). Ki-67 and p53 were detected using clone PP-67 (1:100; Abcam, Cambridge, UK). HER-2 was detected using a mouse monoclonal antibody, clone 45MI (Novocastra, Newcastle upon Tyne, England). The IHC results were scored semiquantitatively on a 4-point scale: $\mathrm{o}$, no immunoreaction; $1+$, faint or equivocal immunoreaction in $<10 \%$ of cells; $2+$, unequivocal, strong immunoreaction in $<30 \%$ of cells; and $3^{+}$, unequivocal, strong immunoreaction in $>30 \%$ of cells. Tumors with $1+, 2+$, or $3+$ expression were interpreted as positive, whereas tumors with no expression were interpreted as negative (Fig. 1). The Ki-67 labeling index (LI) was determined by calculating the percentage of positive nuclei relative to the total number of neoplastic nuclei in 10 high-power fields for every specimen [9]. In this study, Ki-67 LI was divided into four classes: $<5 \%, 5 \%$ to $20 \%, 21 \%$ to $49 \%$, and $>50 \%[8]$. 

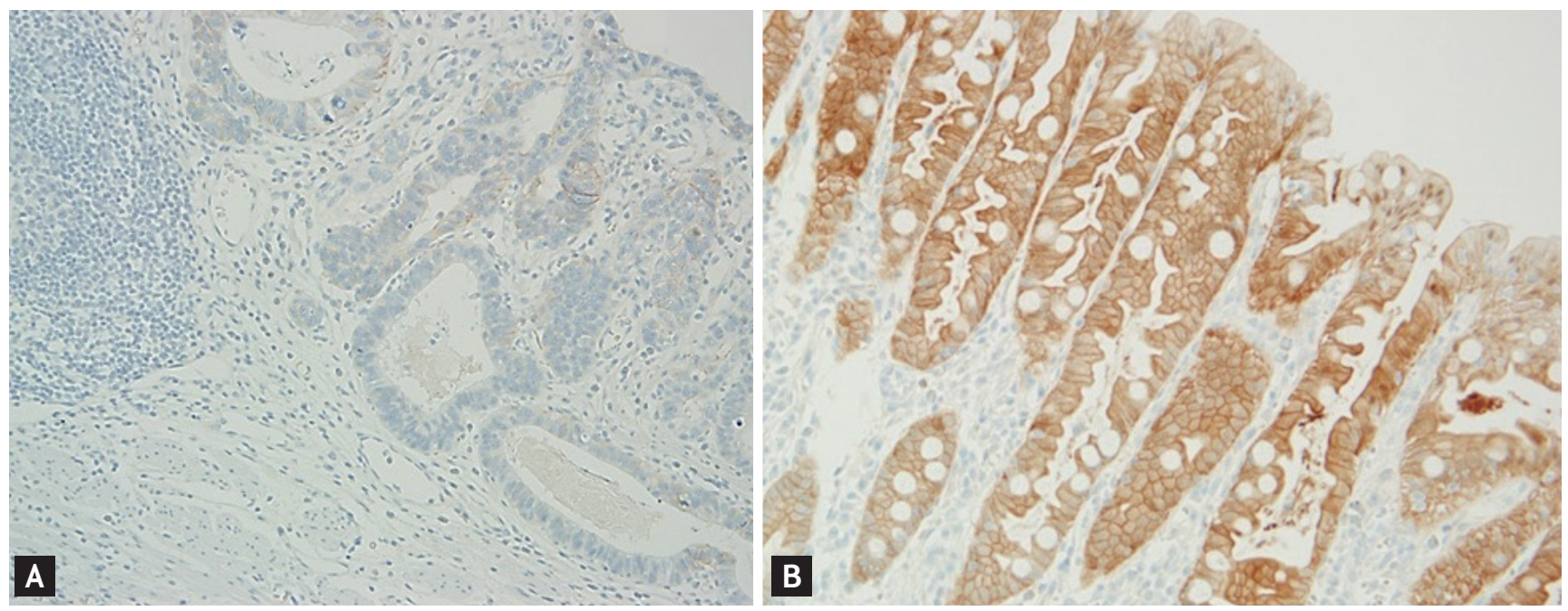

Figure 1. Immunohistochemistry exhibit abnormal membranous expression in the tumor cells of gastric cancer (HER-2). (A) HER-2 negative (×200). (B) HER-2 positive (×400).

\section{Statistical analysis}

We assessed the presence of recurrence and DFS as primary endpoints. DFS was defined as the time interval between the date of gastrectomy and cancer recurrence. We used the SPSS statistical package version 22.0 (IBM, Armonk, NY, USA) for all analyses. Continuous data are expressed as mean \pm standard deviation and were analyzed using an independent-sample $t$ test or the Kruskal-Wallis test. Categorical variables were expressed as quantities and were analyzed using the chi-square test or Fisher's exact test. Survival curves were expressed using the Kaplan-Meier method and log-rank test. All statistical analyses were 2 -sided, and $p<0.05$ was considered statistically significant.

\section{RESULTS}

A total of 505 patients were included in this study. Among them, 279 patients (55.2\%) had EGC and 226 patients had advanced gastric cancer (AGC) (44.8\%). The patients' ages ranged from 27 to 88 years (mean, 63.9 years), and the median follow-up duration was 32.5 months (range, 7 to 70 ). The clinicopathologic features of the enrolled patients and the relation between the expression of genes are shown in Table 1. At the end of the follow-up period, gastric cancer recurrence was diagnosed in 76 cases (15.0\%).
With respect to the IHC results of EGC cases, the total HER-2-positive rate was 29.3\%, and no significant difference was observed between EGC and AGC cases. The p53-, EGFR-, and E-cadherin-positive rates were $78.2 \%(\mathrm{n}=395), 61.4 \%(\mathrm{n}=347)$, and $88.3 \%(\mathrm{n}=446)$, respectively. There was no statistically significant association between 553, EGFR, and E-cadherin positivity and both EGC and AGC (Table 1). The percentage of Ki-67 expression ranged from o\% to $90 \%$ (average, $53 \%$ ). Only Ki-67 had a significantly higher level in AGC cases than in EGC cases $(p=0.011)$. The distribution of Ki-67 LI on pathologic reports was as follows: Ki-67 LI <5\%, 0.6\% of cases; Ki-67 LI 5\% to 20\%, $23.4 \%$ of cases; Ki-67 LI 21\% to $49 \%, 25.3 \%$ of cases; and Ki-67 LI > 50\%, $50.7 \%$ of cases.

With respect to the IHC results in terms of disease recurrence, the associations of p53, EGFR, HER-2, E-cadherin, and Ki-67 positivity with disease recurrence are presented in Table 2. There were no significant associations between the positive expression of p53, EGFR, HER-2, and E-cadherin and tumor recurrence. For Ki-67 expression and $\mathrm{Ki}-67 \mathrm{LI}$, there were also no associations with disease recurrence.

The results of Kaplan-Meier analysis for p53, EGFR, HER-2, E-cadherin, and Ki-67 positivity and disease-free interval are shown in Fig. 2. The results showed no statistically significant associations between p53, EGFR, HER-2, E-cadherin, and Ki-67 positivity and the DFS 
Table 1. Basic characteristics of early and advanced gastric cancers

\begin{tabular}{|c|c|c|c|}
\hline Gross & $\begin{array}{l}\text { Early gastric cancer } \\
\qquad(\mathrm{n}=279)\end{array}$ & $\begin{array}{l}\text { Advanced gastric cancer } \\
\qquad(\mathrm{n}=226)\end{array}$ & $p$ value \\
\hline $\operatorname{Sex}$ & & & 0.926 \\
\hline Female & $83(29.7)$ & $69(30.5)$ & \\
\hline Male & $196(70.3)$ & $157(69 \cdot 5)$ & \\
\hline Age, yr & $63.08 \pm 11.00$ & $64.89 \pm 12.48$ & 0.282 \\
\hline Body mass index, kg/m² & $24.41 \pm 3.30$ & $23.20 \pm 3.39$ & 0.026 \\
\hline Body surface area, $\mathrm{m}^{2}$ & $1.71 \pm 0.17$ & $1.65 \pm 0.18$ & 0.126 \\
\hline \multicolumn{4}{|l|}{ Stage, 7 th AJCC } \\
\hline IA & $246(88.2)$ & o & \\
\hline IB & $23(8.2)$ & $29(12.8)$ & \\
\hline $\operatorname{IIA}(\mathrm{pT} 1, \mathrm{pN} 2 \mathrm{Mo})$ & $6(2.2)$ & $29(12.8)$ & \\
\hline $\operatorname{IIB}\left(\mathrm{pT}_{1}, \mathrm{pN}_{3}, \mathrm{Mo}\right)$ & $4(1.1)$ & $44(19 \cdot 5)$ & \\
\hline III & 0 & $99(43.8)$ & \\
\hline IV & $\mathrm{o}$ & $25(11.1)$ & \\
\hline Disease recurrence & $5(1.8)$ & $71(31.4)$ & \\
\hline $\mathrm{P}_{53}$ & & & 0.530 \\
\hline Positive expression $(+)$ & $212(76.0)$ & $183(81.0)$ & \\
\hline $\operatorname{EGFR}(+)$ & $192(68.8)$ & $155(68.6)$ & 0.730 \\
\hline $\operatorname{HER}-2(+)$ & $89(31.9)$ & $59(26.1)$ & 0.150 \\
\hline E-cadherin $(+)$ & $248(88.9)$ & $198(87.6)$ & 1.000 \\
\hline Ki67 level & $29.29 \pm 29.08$ & $49.81 \pm 56.30$ & $0.011^{\mathrm{a}}$ \\
\hline Ki67 labeling index & & & 0.158 \\
\hline o & $3(1.1)$ & 0 & \\
\hline $1(5 \%-20 \%)$ & $72(25.8)$ & $46(20.4)$ & \\
\hline $2(21 \%-49 \%)$ & $72(25.8)$ & $56(24.8)$ & \\
\hline $3(>50 \%)$ & $132(47 \cdot 3)$ & $124(54 \cdot 9)$ & \\
\hline Tumor size, $\mathrm{cm}$ & $2.8 \pm 1.9$ & $6.2 \pm 3.4$ & $<0.001^{\mathrm{a}}$ \\
\hline Neoadjuvant chemotherapy & & & 0.290 \\
\hline None & $279(100.0)$ & $224(99.1)$ & \\
\hline Incomplete & o & $1(0.4)$ & \\
\hline Complete & 0 & $1(0.4)$ & \\
\hline Location of primary lesion & & & $<0.001^{\mathrm{a}}$ \\
\hline Esophageal gastric junction & o & $2(0.9)$ & \\
\hline Upper third & $24(8.6)$ & $59(26.1)$ & \\
\hline Middle $1 / 3$ & $73(26.2)$ & $28(12.4)$ & \\
\hline Lower $1 / 3$ & $182(65.2)$ & $130(57 \cdot 5)$ & \\
\hline Whole stomach & 0 & $7(3.1)$ & \\
\hline Histologic subtype & & & $<0.001^{\mathrm{a}}$ \\
\hline Tubular adenocarcinoma, well differentiated & $63(22.6)$ & $22(9.7)$ & \\
\hline Tubular adenocarcinoma, moderately differentiated & $95(34 \cdot 1)$ & $77(34 \cdot 1)$ & \\
\hline Tubular adenocarcinoma, poorly differentiated & $51(18.3)$ & $81(35.8)$ & \\
\hline
\end{tabular}


Table 1. Continued

\begin{tabular}{|c|c|c|c|}
\hline Gross & $\begin{array}{l}\text { Early gastric cancer } \\
\qquad(\mathrm{n}=279)\end{array}$ & $\begin{array}{l}\text { Advanced gastric cancer } \\
\qquad(\mathrm{n}=226)\end{array}$ & $p$ value \\
\hline Signet ring cell carcinoma & $56(20.0)$ & $39(17.3)$ & \\
\hline Undifferentiated & $14(5.0)$ & $7(3.1)$ & \\
\hline Lauren's classification & & & $<0.001^{\mathrm{a}}$ \\
\hline Intestinal type & $144(51.6)$ & $86(38.0)$ & \\
\hline Diffuse type & $85(30.5)$ & $91(40.3)$ & \\
\hline Mixed type & $39(14.0)$ & $47(20.8)$ & \\
\hline Unknown & $11(3.9)$ & $2(0.9)$ & \\
\hline Lymphatic invasion & & & $<0.001^{\mathrm{a}}$ \\
\hline Negative & $226(81.0)$ & $62(27 \cdot 4)$ & \\
\hline Positive/+ & $35(12.5)$ & $91(40.3)$ & \\
\hline++ & $4(1.4)$ & $27(11.9)$ & \\
\hline+++ & $6(2.2)$ & $46(20.4)$ & \\
\hline Unknown & $8(2.9)$ & o & \\
\hline Vascular invasion & & & $<0.001^{\mathrm{a}}$ \\
\hline Negative & $264(94 \cdot 6)$ & $161(71.2)$ & \\
\hline Positive/+ & $6(2.2)$ & $54(23.9)$ & \\
\hline++ & 0 & $7(3.1)$ & \\
\hline+++ & $1(0.3)$ & $4(1.8)$ & \\
\hline Unknown & $8(2.9)$ & o & \\
\hline Neural invasion & & & $<0.001^{\mathrm{a}}$ \\
\hline Negative & $265(95.0)$ & $108(47.8)$ & \\
\hline Positive/+ & $6(2.1)$ & $56(24.8)$ & \\
\hline++ & 0 & $26(11.5)$ & \\
\hline+++ & 0 & $36(15 \cdot 9)$ & \\
\hline Unknown & $8(2.9)$ & o & \\
\hline H. pylori infection (histology) & & & 0.540 \\
\hline Negative & $56(20.1)$ & $47(20.8)$ & \\
\hline Positive & $36(12.9)$ & $22(9.7)$ & \\
\hline Unknown & $187(67.0)$ & $157(69 \cdot 5)$ & \\
\hline Surgical treatment & & & $<0.001^{\mathrm{a}}$ \\
\hline Total gastrectomy & $27(9.7)$ & $93(41.2)$ & \\
\hline Distal subtotal gastrectomy & $244(87.5)$ & $133(58.8)$ & \\
\hline Proximal gastrectomy & $7(2.5)$ & o & \\
\hline Pylorus-preserving gastrectomy & $1(0.4)$ & o & \\
\hline Disease-free interval (DFS) & $840.9 \pm 42.2$ & $1,032.9 \pm 420.7$ & $<0.001^{\mathrm{a}}$ \\
\hline
\end{tabular}

Values are presented as number (\%) or mean \pm standard deviation.

AJCC, American Joint Committee on Cancer; EGFR, epidermal growth factor receptor; HER-2, human epidermal growth factor receptor 2; DFS, disease-free survival.

${ }^{\text {a }}$ Statistically significant. 
Table 2. The positive expression rate of immunohistochemical staining according to the disease recurrence

\begin{tabular}{|c|c|c|c|}
\hline $\begin{array}{l}\text { Immunohisto- } \\
\text { chemical stain of } \\
\text { biomarkers }\end{array}$ & $\begin{array}{c}\text { No } \\
\text { recurrence } \\
(\mathrm{n}=429)\end{array}$ & $\begin{array}{l}\text { Recurrence } \\
\quad(n=76)\end{array}$ & $p$ value \\
\hline p53 & & & 0.827 \\
\hline Negative & $93(21.7)$ & $17(22.3)$ & \\
\hline Positive & $336(78.3)$ & $59(77 \cdot 7)$ & \\
\hline EGFR & & & 0.875 \\
\hline Negative & $136(31.7)$ & $22(28.9)$ & \\
\hline Positive & $293(68.3)$ & $54(71.1)$ & \\
\hline HER-2 & & & 0.574 \\
\hline Negative & $301(70.2)$ & $56(73.7)$ & \\
\hline Positive & $128(29.8)$ & $20(26.3)$ & \\
\hline E-cadherin & & & 0.564 \\
\hline Negative & $53(12.4)$ & $7(9.2)$ & \\
\hline Positive & $376(87.6)$ & $69(90.8)$ & \\
\hline Ki67 level & $52.7 \pm 29 \cdot 3$ & $53 \cdot 3 \pm 30.1$ & 0.875 \\
\hline Ki67 labeling index & & & 0.834 \\
\hline 0 & $3(0.7)$ & o & \\
\hline 1 & $100(23 \cdot 3)$ & $18(23.7)$ & \\
\hline 2 & $107(24.9)$ & $21(27.6)$ & \\
\hline 3 & $219(51.0)$ & $37(48.7)$ & \\
\hline
\end{tabular}

Values are presented as number (\%) or mean \pm standard deviation.

EGFR, epidermal growth factor receptor; HER-2, human epidermal growth factor receptor 2 .

of patients. Concerning metastatic lymph nodes, there were also no significant differences according to p53, EGFR, HER-2, E-cadherin, and Ki-67 positivity.

There were three recurrences in stage I gastric cancer patients (Supplementary Table 1). In the subgroup analysis of pathologic stage I (stage IA + IB, $n=269$ ) gastric cancer cases, HER-2-positive gastric cancer tended to occur in older patients $(p=0.01)$ and in the upper onethird of the stomach compared with HER-2-negative gastric cancer $(p=0.01)$. Furthermore, HER-2 positivity was strongly related to disease recurrence $(p=0.01)$, lymphatic invasion $(p=0.03)$, and vascular invasion $(p=0.03)$ (Table 3).

Between DFS and HER-2 positivity in pathologic stage I (stage IA + IB) gastric cancer cases, a statistically sig- nificant correlation ( $p=0.01$ ) was observed (Fig. 3). IHC staining showed that none of the five biomarkers had prognostic value in gastric cancer.

\section{DISCUSSION}

In the new era when postoperative adjuvant chemotherapy for gastric cancer is generalized, we aimed to evaluate the possible relationship between p53, EGFR, HER2, E-cadherin, and Ki-67 positivity in the prognosis of patients with gastric cancer. We performed subgroup analyses to determine the significance of the expression of various biomarkers in gastric cancer. Our results revealed that AGC cases had higher levels of Ki-67 expression than EGC cases, and the expression of various biomarkers including p53, EGFR, HER-2, E-cadherin, and $\mathrm{Ki}-67$ had limited value in predicting the prognosis of patients. However, in stage I gastric cancer cases, HER-2-positive expression was significantly associated with disease recurrence and lymphovascular invasion.

The gene for the HER-2 protein (also known as ErbB2, c-erbB2, or Her2/neu) is a proto-oncogene expressed in several solid tumors such as breast cancer [10]. This gene is located on chromosome $17 \mathrm{q}$ and is encoded by a $185-\mathrm{kDa}$ transmembrane tyrosine kinase receptor protein that is a member of the HER family, consisting of HER-1 (EFGR), HER-2, HER-3, and HER-4. HER-2 has a predictive value for trastuzumab therapy (Herceptin, Roche/Genentech, Basel, Switzerland), a kind of HER-2-targeted therapy in AGC [11,12]. Previous studies have shown that a HER-2-postive status identified either using IHC analysis or fluorescence in situ hybridization has a negative prognostic value related to histopathologic type, differentiation status, serosal invasion, lymph node metastasis, disease progression, and survival [13-16]. However, it is unlikely that this trend is consistent with the reported trend in breast cancer, and the results are still inconclusive in gastric cancer $[17,18]$. Our results showed that HER-2-positive expression had little prognostic value in EGC and AGC, and did not have a predictive value for lymph node metastasis and disease recurrence. The reason for this discrepancy is that the prevalence of HER-2 overexpression in gastric cancer varies among different studies [11,12,19-21]. Previous studies that investigated patients with gastric can- 

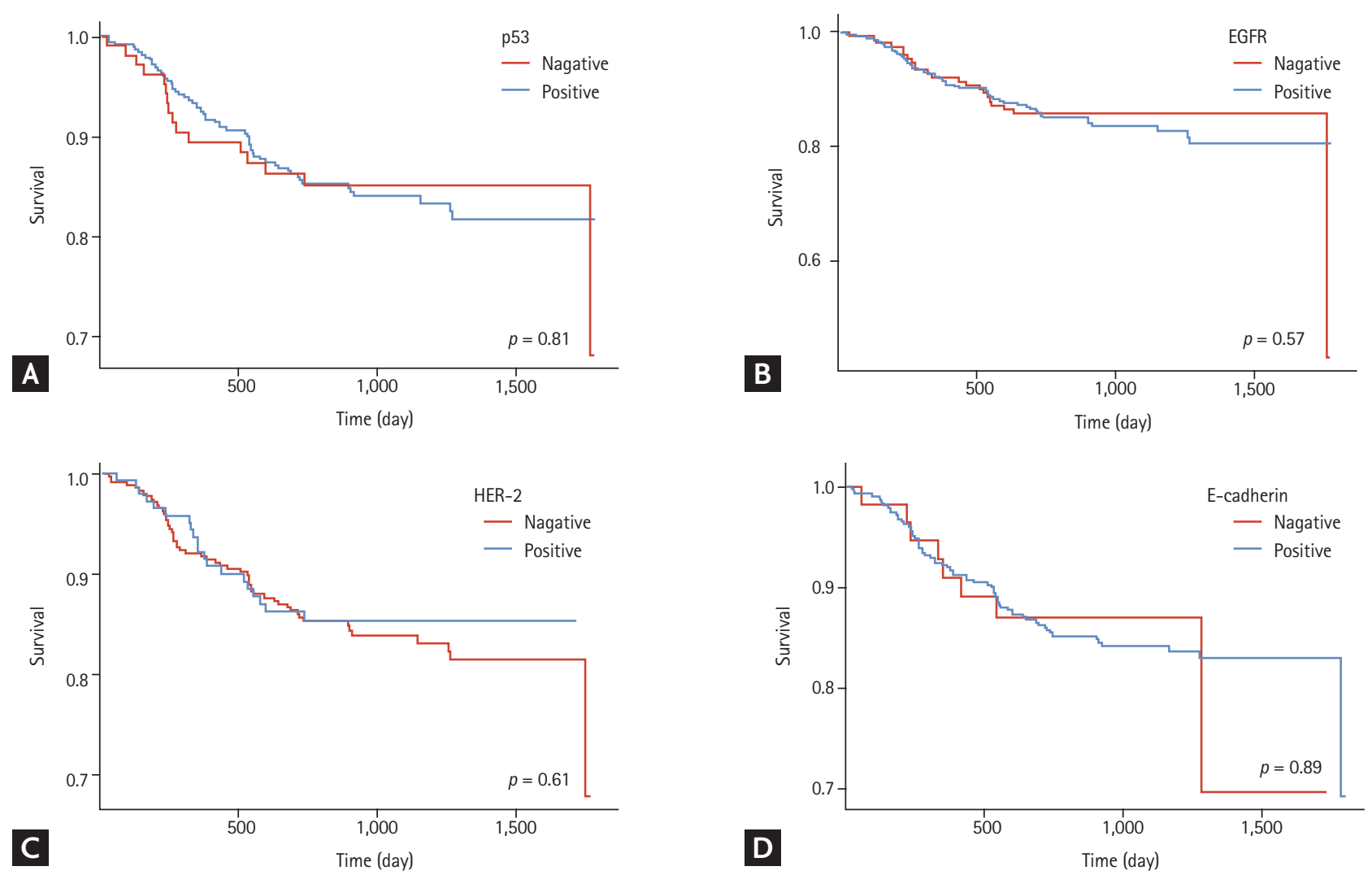

Figure 2. Kaplan-Meier curve of disease-free interval in patients with gastric cancers that expressed the various biomarkers. (A) p53, (B) epidermal growth factor receptor (EGRF), (C) human epidermal growth factor receptor 2 (HER-2), (D) E-cadherin.

cer reported various frequencies of HER-2 overexpression (6\% to $53.4 \%)$ and gene amplification ( $16 \%$ to $27 \%)$ $[11,12,22-25]$. In this study, the incidence of HER-2-positive gastric cancer was 29.3\%. Second, different studies investigated various primary outcomes including lymph node metastasis, nodal status, advanced disease stage, overall survival, 5-year survival rate, and disease-specific survival. Third, the role of adjuvant chemotherapy after curative resection has been overlooked, especially in AGC cases. In the 2000s, adjuvant chemotherapy was administered as a standard therapy, as recommended by the clinical practice guidelines for gastric cancer in Korea. For AGC beyond stage IIB, adjuvant chemotherapy is strongly recommended. From this viewpoint, it is difficult to accept previous results showing the good prognostic value of HER-2 positivity in gastric cancer before the 2000s.

It is noteworthy that a HER-2-positive expression was the sole prognostic factor for microscopic lymphovas- cular invasion and disease recurrence in stage I (IA and IB) gastric cancer. Previously, the follow-up records of 1475 patients with EGC treated at the Tokyo National Cancer Center showed a recurrence rate for all EGC cases of at least $1.9 \%$ and a recurrence rate for EGC with submucosal invasion of 3.6\% [26]. Considering this report, it can be surmised that most recurrence cases in mucosal cancer involve HER-2-positive gastric cancers. Furthermore, no disease recurrence was detected in HER-2-negative stage I gastric cancer cases.

Gastric cardia cancer or esophagogastric junctional cancer was found to have a negative prognostic impact compared with gastric non-cardia cancer $[27,28]$. The main causes were the higher frequency of advanced-staged cancers and the presence of anatomical defects (partially developed serosa in the proximal onethird of the stomach and local lymphatic drainage that was prone to advanced lymph node stage, including the splenic, celiac, or portal lymph nodes). In our results, 
Table 3. The relation between positive expression HER-2 and disease recurrence in $p$ stage I $($ stage IA $+I B, n=269)$ gastric cancers

\begin{tabular}{|c|c|c|c|}
\hline p stage I & $\begin{array}{c}\text { HER-2 positive } \\
\text { gastric cancer }(n=87)\end{array}$ & $\begin{array}{c}\text { HER-2 negative } \\
\text { gastric cancer }(n=182)\end{array}$ & $p$ value \\
\hline Male sex & 65 & 121 & 0.17 \\
\hline Age, yr & $65.57 \pm 9.80$ & $62.14 \pm 11.31$ & $0.01^{\mathrm{a}}$ \\
\hline BMI, $\mathrm{kg} / \mathrm{m}^{2}$ & $24.36 \pm 3.26$ & $24 \cdot 54 \pm 3 \cdot 31$ & 0.68 \\
\hline Current smoking & 20 & 43 & 0.91 \\
\hline Alcohol drinking & 34 & 78 & 0.56 \\
\hline CEA & $3.01 \pm 2.88$ & $2.59 \pm 2.56$ & 0.24 \\
\hline CA19-9 & $9.081 \pm 12.03$ & $10.72 \pm 19.41$ & 0.50 \\
\hline Depth mucosa & 36 & 103 & 0.67 \\
\hline \multicolumn{4}{|l|}{ Submucosa } \\
\hline $\mathrm{SM} 1$ & 22 & 24 & \\
\hline $\mathrm{SM} 2$ & 15 & 19 & \\
\hline $\mathrm{SM}_{3}$ & 13 & 35 & \\
\hline Muscle, proper (PM) & 1 & 1 & \\
\hline Metastatic lymph node & 9 & 14 & 0.47 \\
\hline Lymphatic invasion & 19 & 22 & $0.03^{\mathrm{a}}$ \\
\hline Vascular invasion & 19 & 22 & $0.03^{\mathrm{a}}$ \\
\hline Location & & & $0.01^{\mathrm{a}}$ \\
\hline Upper $1 / 3$ & 13 & 11 & \\
\hline $\operatorname{Mid} 1 / 3$ & 18 & 40 & \\
\hline Low $1 / 3$ & 56 & 131 & \\
\hline Histologic subtype & & & 0.21 \\
\hline Tubuar adenocarcinoma well differentiated & 26 & 35 & \\
\hline Tubular adenocarcinoma moderately differentiated & 30 & 63 & \\
\hline Tubular adenocarcinoma poorly differentiated & 12 & 34 & \\
\hline SRC + undifferentiated & 19 & 50 & \\
\hline Disease recurrence & $3(3.4)$ & 0 & $0.01^{\mathrm{a}}$ \\
\hline
\end{tabular}

Values are presented as mean \pm standard deviation or number $(\%)$.

HER-2, human epidermal growth factor receptor 2; BMI, body mass index; CEA, carcinoembryonic antigen; CA19-9, carbohydrate antigen 19-9; SM, submucosa; SRC, signet ring cell carcinoma.

${ }^{\text {a }}$ Statistically significant.

HER-2-positive gastric cancer had a tendency to occur in old patients and in a proximal location, and it is likely that HER-2 positivity is involved in the poor prognosis of gastric cardia cancer.

In addition, we evaluated the association of EGFR, p53, E-cadherin, and Ki-67 expression with disease prognosis; however, we did not find any significant associations. EGFR, also known as ErbB-1 or HER-1, is one of the possible genes associated with several types of can- cer, including gastric cancer [29,30]. Moreover, the prognostic value of $\mathrm{p} 53$, which plays an important role in cell cycle arrest and the induction of apoptosis, has been evaluated in gastric cancer [31-33]. A recent meta-analysis revealed that a positive 553 expression is related to poor prognosis $[34,35]$. E-cadherin is the prototype of the E-cadherin class that links to catenins to form the cytoskeleton, and it has a role in infiltration and metastasis as well as functions as a tumor suppressor in cancer de- 


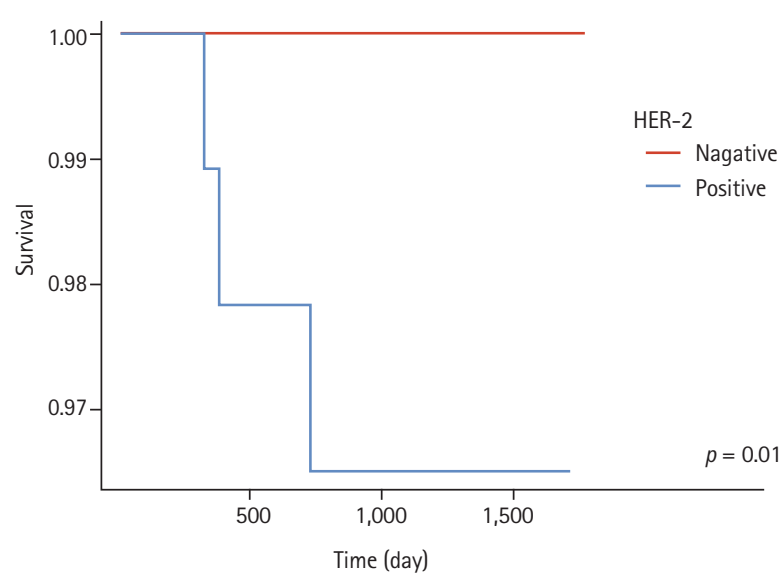

Figure 3. Kaplan-Meier curve of disease-free interval in patients with stage $\mathrm{pT} 1 \mathrm{IA}+\mathrm{IB})$ that had the positive expression of human epidermal growth factor receptor 2 (HER-2). DFS, disease-free survival.

velopment and growth [36]. Although the evidence is inconclusive, several studies have shown that E-cadherin is associated with gastric cancer [35,37-39]. Ki-67, a marker of tumor cell proliferation, is expressed in all cell cycles except Go and early G1, and thus has been studied in several malignant tumors. However, its role in gastric cancer remains unclear $[40,41]$. It is difficult to conclude the relationship between cancer development and prognosis and the expression status of these biomarkers in gastric cancer. Therefore, additional studies are needed because of the possibility that the different types and locations of gastric cancer would show different results.

The limitation of the study was that the data were reviewed retrospectively. Since data from patients undergoing surgical treatment were analyzed retrospectively, it was challenging to fully evaluate the results of all gastric cancer patients and the role of various factors such as $\mathrm{H}$. pylori bacteria that influence the occurrence of gastric cancer. To analyze the role of immunohistochemical staining of early stage gastric cancer, more accurate data are needed, including patients undergoing endoscopic procedures. However, immunohistochemical staining was not performed in all these patients, so only patients who underwent surgery were analyzed. In addition, since it was a single-center study, the number of patients was small. Therefore, there are some limitations in drawing conclusions on the role of HER-2 in patients with stage I gastric cancer. In order to validate our findings, a well-designed, multicenter prospective study is necessary.

In conclusion, we investigated the expression of p53, EGFR, HER-2, E-cadherin, and Ki-67 through IHC staining to determine the association of these biomarkers with the prognosis of gastric cancer. Our study showed that these biomarkers still have limited value and do not qualify as clinical predictors. Only HER-2 positivity in stage I (IA and IB) gastric cancer was associated with recurrence; thus, HER-2 could be a possible biomarker for the prediction of recurrence in patients with stage I gastric cancer.

\section{KEY MESSAGE}

1. In advanced gastric cancers, 5-year survival rate is less than $30 \%$ and the tumor recurrence or metastasis after curative resection is more than $50 \%$.

2. It was believed that clinical significance of human epidermal growth factor receptor 2 (HER2) positive gastric cancers showed unfavorable prognostic indicator. Unfortunately, several studies have reported the inconsistent results, and it is still inconclusive.

3. HER-2-positive gastric cancer had a tendency to occur in old patients and in a proximal location. HER-2 positivity was strongly related to disease recurrence, lymphatic invasion, and vascular invasion in stage I (IA and IB) gastric cancers. HER-2 positivity could be a good biomarker for prognosis prediction.

\section{Conflict of interest}

No potential conflict of interest relevant to this article was reported.

\section{REFERENCES}

1. Mathers CD, Shibuya K, Boschi-Pinto C, Lopez AD, Murray CJ. Global and regional estimates of cancer mortality and incidence by site: I. Application of regional cancer survival model to estimate cancer mortality distribution 
by site. BMC Cancer 2002;2:36.

2. Karimi P, Islami F, Anandasabapathy S, Freedman ND, Kamangar F. Gastric cancer: descriptive epidemiology, risk factors, screening, and prevention. Cancer Epidemiol Biomarkers Prev 2014;23:700-713.

3. Sakuramoto S, Sasako M, Yamaguchi T, et al. Adjuvant chemotherapy for gastric cancer with $\mathrm{S}-1$, an oral fluoropyrimidine. N Engl J Med 2007;357:1810-1820.

4. Bang YJ, Kim YW, Yang HK, et al. Adjuvant capecitabine and oxaliplatin for gastric cancer after D2 gastrectomy (CLASSIC): a phase 3 open-label, randomised controlled trial. Lancet 2012;379:315-321.

5. Correia M, Machado JC, Ristimaki A. Basic aspects of gastric cancer. Helicobacter 2009;14 Suppl 1:36-40.

6. Marrelli D, de Stefano A, de Manzoni G, Morgagni P, Di Leo A, Roviello F. Prediction of recurrence after radical surgery for gastric cancer: a scoring system obtained from a prospective multicenter study. Ann Surg 2005;241:247255 .

7. Washington K. 7th Edition of the AJCC cancer staging manual: stomach. Ann Surg Oncol 2010;17:3077-3079.

8. Lazar D, Taban S, Sporea I, et al. Ki-67 expression in gastric cancer: results from a prospective study with longterm follow-up. Rom J Morphol Embryol 2010;51:655-661.

9. Ko GH, Go SI, Lee WS, et al. Prognostic impact of Ki-67 in patients with gastric cancer: the importance of depth of invasion and histologic differentiation. Medicine (Baltimore) 2017;96:e7181.

10. Slamon DJ, Clark GM, Wong SG, Levin WJ, Ullrich A, McGuire WL. Human breast cancer: correlation of relapse and survival with amplification of the HER-2/neu oncogene. Science 1987;235:177-182.

11. Boku N. HER2-positive gastric cancer. Gastric Cancer 2014;17:1-12.

12. Park DI, Yun JW, Park JH, et al. HER-2/neu amplification is an independent prognostic factor in gastric cancer. Dig Dis Sci 2006;51:1371-1379.

13. Ansari J, Chehrei A, Amini M, Alizade SH, Sanei MH. The prognostic significance of Her2-neu over expression in gastric carcinomas. Iran J Cancer Prev 2011;4:170-176.

14. Kim JW, Im SA, Kim M, et al. The prognostic significance of HER2 positivity for advanced gastric cancer patients undergoing first-line modified FOLFOX-6 regimen. Anticancer Res 2012;32:1547-1553.

15. Movagharnejad K, Sharbatdaran M, Sheffaee S, Kashifard M, Sedaghat S. HER-2/neu marker examination using im- munohistochemical method in patients suffering from gastric adenocarcinoma. Int J Mol Cell Med 2013;2:199203.

16. Yonemura Y, Ninomiya I, Yamaguchi A, et al. Evaluation of immunoreactivity for erbB-2 protein as a marker of poor short term prognosis in gastric cancer. Cancer Res 1991;51:1034-1038.

17. Roh JK, Paik S, Chung HC, et al. Overexpression of erbB2 protein in gastric adenocarcinoma: a potential role in therapeutic response to adjuvant 5-FU-doxorubicin regimen. Gan To Kagaku Ryoho 1992;19(8 Suppl):1207-1219.

18. Jorgensen JT, Hersom M. HER2 as a prognostic marker in gastric cancer: a systematic analysis of data from the literature. J Cancer 2012;3:137-144.

19. Nagaraja V, Eslick GD. HER2 expression in gastric and oesophageal cancer: a meta-analytic review. J Gastrointest Oncol 2015;6:143-154.

20. Feizy A, Karami A, Eghdamzamiri R, Moghimi M, Taheri H, Mousavinasab N. HER2 expression status and prognostic, diagnostic, and demographic properties of patients with gastric cancer: a single center cohort study from Iran. Asian Pac J Cancer Prev 2018;19:1721-1725.

21. Oono Y, Kuwata T, Takashima K, et al. Human epidermal growth factor receptor 2-, epidermal growth factor receptor-, and mesenchymal epithelial transition factor-positive sites of gastric cancer using surgical samples. Gastric Cancer 2019;22:335-343.

22. Wang HB, Liao XF, Zhang J. Clinicopathological factors associated with HER2-positive gastric cancer: a meta-analysis. Medicine (Baltimore) 2017;96:e8437.

23. Gravalos C, Jimeno A. HER2 in gastric cancer: a new prognostic factor and a novel therapeutic target. Ann Oncol 2008;19:1523-1529.

24. Jorgensen JT. Targeted HER2 treatment in advanced gastric cancer. Oncology 2010;78:26-33.

25. Sano T, Sasako M, Kinoshita T, Maruyama K. Recurrence of early gastric cancer: follow-up of 1475 patients and review of the Japanese literature. Cancer 1993;72:3174-3178.

26. Amini N, Spolverato G, Kim Y, et al. Clinicopathological features and prognosis of gastric cardia adenocarcinoma: a multi-institutional US study. J Surg Oncol 2015;111:285292.

27. Okholm C, Svendsen LB, Achiam MP. Status and prognosis of lymph node metastasis in patients with cardia cancer: a systematic review. Surg Oncol 2014;23:140-146.

28. Herbst RS. Review of epidermal growth factor receptor 
biology. Int J Radiat Oncol Biol Phys 2004;59(2 Suppl):21-26.

29. Paez JG, Janne PA, Lee JC, et al. EGFR mutations in lung cancer: correlation with clinical response to gefitinib therapy. Science 2004;304:1497-1500.

30. Begnami MD, Fregnani JH, Nonogaki S, Soares FA. Evaluation of cell cycle protein expression in gastric cancer: cyclin $\mathrm{B} 1$ expression and its prognostic implication. Hum Pathol 2010;41:1120-1127.

31. Pinto-de-Sousa J, Silva F, David L, et al. Clinicopathological significance and survival influence of p53 protein expression in gastric carcinoma. Histopathology 2004;44:323-331.

32. Ye YW, Zhang X, Zhou Y, et al. The correlations between the expression of FGFR4 protein and clinicopathological parameters as well as prognosis of gastric cancer patients. J Surg Oncol 2012;106:872-879.

33. Yildirim M, Kaya V, Demirpence O, Gunduz S, Bozcuk H. Prognostic significance of $\mathrm{p} 53$ in gastric cancer: a metaanalysis. Asian Pac J Cancer Prev 2015;16:327-332.

34. Wei K, Jiang L, Wei Y, et al. The prognostic significance of p53 expression in gastric cancer: a meta-analysis. J Cancer Res Clin Oncol 2015;141:735-748.

35. Chan AO. E-cadherin in gastric cancer. World J Gastroen- terol 2006;12:199-203.

36. Xing X, Tang YB, Yuan G, et al. The prognostic value of E-cadherin in gastric cancer: a meta-analysis. Int J Cancer 2013;132:2589-2596.

37. Czyzewska J, Guzinska-Ustymowicz K, Ustymowicz M, Pryczynicz A, Kemona A. The expression of E-cadherin-catenin complex in patients with advanced gastric cancer: role in formation of metastasis. Folia Histochem Cytobiol 2010;48:37-45.

38. Kawanishi K, Doki Y, Shiozaki H, et al. Correlation between loss of E-cadherin expression and overexpression of autocrine motility factor receptor in association with progression of human gastric cancers. Am J Clin Pathol 2000;113:266-274.

39. Kakeji Y, Korenaga D, Tsujitani S, Haraguchi M, Maehara Y, Sugimachi K. Predictive value of Ki-67 and argyrophilic nucleolar organizer region staining for lymph node metastasis in gastric cancer. Cancer Res 1991;51:3503-3506.

40. Boger C, Behrens HM, Rocken C. Ki67: an unsuitable marker of gastric cancer prognosis unmasks intratumoral heterogeneity. J Surg Oncol 2016;113:46-54.

41. Huang G, Chen S, Wang D, et al. High Ki67 expression has prognostic value in surgically-resected $\mathrm{T}_{3}$ gastric adenocarcinoma. Clin Lab 2016;62:141-153. 


\section{KJIM}

Supplementary Table 1. Characteristic of the recurrent patient in the stage I gastric cancer patients

\begin{tabular}{|c|c|c|c|}
\hline Characteristic & Case 1 & Case 2 & Case 3 \\
\hline Age, yr & 56 & 56 & 69 \\
\hline Sex & Male & Male & Male \\
\hline Body mass index, $\mathrm{kg} / \mathrm{m}^{2}$ & 26.5 & 23.8 & 23.8 \\
\hline Current smoking & Non-smoker & Smoker & Non-smoker \\
\hline Alcohol drinking & Social drinking & None & None \\
\hline CEA & 1.15 & 1.55 & 9.66 \\
\hline CA19-9 & o & 197.2 & $14 \cdot 3$ \\
\hline Depth & $\mathrm{SM}_{3}$ & SM & $\mathrm{SM}_{1}$ \\
\hline Tumor size, cm & 6 & $4 \cdot 5$ & 1.5 \\
\hline Lymphatic invasion & Positive & Positive & Negative \\
\hline Vascular invasion & Positive & Positive & Negative \\
\hline Stage, 7th AJCC & IB & IB & IA \\
\hline Location & Low $1 / 3$ & Low $1 / 3$ & Low $1 / 3$ \\
\hline Histologic subtype & $\begin{array}{l}\text { Tubular adenocarcinoma, } \\
\text { moderately differentiated }\end{array}$ & $\begin{array}{c}\text { Tubular adenocarcinoma, } \\
\text { poorly differentiated }\end{array}$ & $\begin{array}{l}\text { Tubular adenocarcinoma, } \\
\text { well differentiated }\end{array}$ \\
\hline \multicolumn{4}{|l|}{ Lauren's classification } \\
\hline p53 & Positive & Positive & Positive \\
\hline EGFR & Negative & Positive & Positive \\
\hline HER-2 & Positive & o & Positive \\
\hline E-cadherin & Positive & Positive & Positive \\
\hline Ki67 level & 90 & 90 & 60 \\
\hline Surgical treatment & Distal subtotal gastrectomy & Distal subtotal gastrectomy & Distal subtotal gastrectomy \\
\hline
\end{tabular}

